\title{
Phytochemical and Biological Investigation of Stevia rebaudiana (Bert.) Leaves Grown in Bangladesh
}

\author{
Chand Sultana ${ }^{1}$, Md. A.K. Azad ${ }^{2}$, Md. Mominur Rahman ${ }^{2}$, \\ Md. Abdul Muhit ${ }^{1}$ and S. M. Abdur Rahman ${ }^{1}$
}

${ }^{1}$ Department of Clinical Pharmacy and Pharmacology, University of Dhaka, Dhaka-1000, Bangladesh.

${ }^{2}$ Department of Pharmacy, Daffodil International University, Dhaka-1207, Bangladesh.

(Received: November 06, 2020; Accepted: December 01, 2020; Published (web): December 10, 2020)

\begin{abstract}
Three fractions obtained by Kupchan partitioning of $70 \%$ methanol extract of leaves of Stevia rebaudiana with $n$-hexane, dichloromethane and ethyl acetate designated by HSR, DSR and ESR were investigated for their antioxidant and antimicrobial activities. HSR and ESR exhibited prominent free radical scavenging activity having $\mathrm{IC}_{50}$ value of 11.59 and $10.38 \mu \mathrm{g} / \mathrm{ml}$ compared to standard, ascorbic acid $\left(\mathrm{IC}_{50}\right.$ value $\left.6.05 \mu \mathrm{g} / \mathrm{ml}\right)$. HSR and ESR also demonstrated significant antibacterial activity by disc diffusion method on some Gram-positive and Gramnegative bacteria. Among the fractions ESR showed the highest antioxidant and antibacterial activity. No significant antifungal activity was observed for any fraction. Preliminary phytochemical screening of all fractions showed the presence of alkaloids, saponin, flavonoids, tannin, carbohydrate and triterpenoids. Total three compounds have been isolated from ESR fraction among which two known compounds (1-2) were characterized as quercitrin (1) and physcion (2) through 1D NMR spectroscopic technique and other one could be a 9,10anthraquinone derivative which was not characterized yet. The compound physcion (2) is first time report from the plant Stevia rebaudiana.
\end{abstract}

Key words: Quercitrin, Physcion, Candy leaf, Antibacterial, Free radical, DPPH, and Stevia rebaudiana.

\section{INTRODUCTION}

Stevia rebaudiana (Bertoni) commonly known as "sugar leaf" or "candy leaf "belongs to the family Asteraceae. ${ }^{1}$ This perennial sweet herb is distributed in humid and wet environment and is indigenous to Brazil and Paraguay. ${ }^{2}$ Stevia is being used as a source of natural sweetener due to its high content in sweet diterpene glycosides, such as isosteviol, stevioside, rebaudiosides (A, B, C, D, E and F), steviolbioside and dulcoside A. About 100 or more compounds have been identified in Stevia rebaudiana, the best known of which are the steviol glycosides, particularly stevioside, rebaudioside $\mathrm{A}$ and $\mathrm{C}$ being the most abundant which are 250-300 times more sweet than $\operatorname{sugar}^{3}$ and less common bioactive constituents are phenolic compounds and flavonoids

Correspondence to: S. M. Abdur Rahman

E-mail: smarahman@du.ac.bd

Dhaka Univ. J. Pharm. Sci. 19(2): 191-197, 2020 (December) DOI: https://doi.org/10.3329/dujps.v19i2.50636 like quercetin, luteolin, apegenin., ${ }^{4,5}$ Beside glycosides, the leaves of stevia also contain other phytochemicals, such as flavonoids, phenolic acids, fatty acids, proteins and vitamins. Several studies have reported that stevia extracts strived significant antimicrobial, anti-hypertensive, anti-inflammatory, hepatoprotective and immunomodulatory activities, due to its high abundance in bioactive phytoconstituents. $^{6-8}$ Now-a-days, stevia is widely cultivated in many countries of South East Asian region including Bangladesh owing to its many health benefits. The phytochemical compositions and bioactivity of any plant and plant-derived products varies greatly with the change of climate and geographical conditions such as soil, water cultivation process etc. In the present time pathogenic and spoilage microorganisms has increased due to the increase outbreaks of several type of new microorganism. ${ }^{9}$ To our concern a very few scientific trials on antimicrobial and the antioxidant capacity of 
S. rebaudiana cultivated in Bangladesh has been evaluated. The objective of the present study was to conduct a bioactivity directed phytochemical investigation on $S$. rebaudiana. In this study, antioxidant and antimicrobial activities of different fractions derived from leaves of $S$. rebaudiana will be investigated followed by isolation of active components from the different fractions of crude extract.

\section{MATERIALS and METHODS}

Collection of plant materials. The leaves of Stevia rebaudiana (SR) were collected from Brac Nursery located in Joydebpur, Gazipur in late March 2018. The exsiccated plant samples were identified by Mr. Sardar Nasir Uddin, Principal Scientific Officer, Bangladesh National Herbarium, Mirpur, Dhaka where a voucher specimen has been deposited for future reference (Accession number: DACB38588).

Instruments and materials. Column chromatography was conducted on silica gel (60-120 mesh size, E-Merck) whereas thin layer chromatography (TLC) and preparative TLC were carried out on precoated silica gel $60 \quad \mathrm{~F}_{254}$ (Aluminium sheets, E-Merk, Germany). ${ }^{1} \mathrm{H}$ and ${ }^{13} \mathrm{C}$ NMR spectral data were recorded on Bruker 400 and $100 \mathrm{MHz}$, respectively. Ascorbic acid and ciprofloxacin were obtained as gifts from Square Pharmaceuticals Ltd; Bangladesh and DPPH (1, 1diphenyl-2- picrylhydrazyl) was purchased from Sigma Chemical Co. Ltd (St. Louis, MO, USA).

Extraction. The fresh leaves were shade dried and powdered $(1 \mathrm{~kg})$ which were extracted with $70 \%$ methanol at room temperature for 15 days. White cotton followed by Whatman filter paper number-1 was used to get clean filtrate. The filtrate was concentrated by using a rotary evaporator to obtain greenish black mass $(100 \mathrm{~g})$. The crude extract was then fractioned by the modified Kupchan partitioning protocol $^{10}$ to yield n-hexane, dichlormethane and ethyl acetate soluble materials of $S$. rebaudiana designated as HSR, DSR and ESR having 8\%, 10\% and $15 \% \mathrm{w} / \mathrm{w}$ yield, respectively.
Phytochemical screening. Phytochemical analysis of the different extracts was performed with the standard methods outlined by Nayek and Pereira. ${ }^{11}$

Isolation of compounds from ESR fraction. ESR fraction (500 $\mathrm{mg}$ ) was used to isolate pure components by using column chromatography. At first, the ESR fraction was dissolved in methanol and mixed with small amount of silica gel (mesh size 60$120,1 \mathrm{~g}$ sample) to make dry sample for column chromatography (CC). After complete mixing with spatula, methanol was initially evaporated and finally it was completely dried in a vacuum desiccator. The fine adsorbed sample was then loaded on a clean and dry glass column packed with silica gel (60-120 mesh size) and eluted with ethyl acetate: acetic acid: water (9:0.5:0.5) in order of increasing polarities. Each column fraction $(10 \mathrm{ml})$ collected in test tubes was monitored by TLC. Fractions with identical TLC features were combined and a total 10 (A-J) fractions obtained. The pooled fractions were then rechromatographed by preparative thin layer chromatography (PTLC) using ethyl acetate: acetic acid: water (6:2:2) system to afford yellowish crystals of compound 1 ( $8 \mathrm{mg}$ ), white powder of compound 2 $(10 \mathrm{mg})$ and white crystals of compound $3(6 \mathrm{mg})$ with $R_{f}$ values of $0.3,0.5$ and 0.7 respectively. Structure of the isolates was characterized by ${ }^{1} \mathrm{H}-$ NMR and ${ }^{13} \mathrm{C}$-NMR spectral data.

Properties of isolated compound. Quercitrin (1): Pale yellow needle crystals, ${ }^{1} \mathrm{H}$ NMR $(400 \mathrm{MHz}$, $\left.\mathrm{CD}_{3} \mathrm{OD}\right): \delta 7.35\left(1 \mathrm{H}, \mathrm{d}, J=1.5 \mathrm{~Hz}, \mathrm{H}-2^{\prime}\right), 7.30(1 \mathrm{H}$, dd, $J=8.0$ and $\left.1.5 \mathrm{~Hz}, \mathrm{H}-6^{\prime}\right), 6.9(1 \mathrm{H}, \mathrm{d}, \mathrm{J}=7.5 \mathrm{~Hz}$, H-5'), $6.37(1 \mathrm{H}, \mathrm{d}, J=1.5 \mathrm{~Hz}, \mathrm{H}-8), 6.19(1 \mathrm{H}, \mathrm{d}, J=1.5$ Hz, H-6), 5.34 (1H, br. s, H-1"), 0.82 (3H, d, J=3.5 $\mathrm{Hz}, \mathrm{H}-6 ") .{ }^{13} \mathrm{C}$ NMR (100 MHz, $\left.\mathrm{CD}_{3} \mathrm{OD}\right): \delta$ 148.4(C2), 134.8(C-3), 177.9(C-4), 161.8(C-5), 98.7(C-6), 164.6(C-7), 93.6(C-8), 157.8(C-9), 104.4(C-10), 121.4(C-1'), 115.6(C-2'), 157.2(C-3'), 145.1(C-4'), 115.1(C-5'), 121.6(C-6'), 102.1(C-1"), 70.6(C-1"), 70.7(C-1"), 71.9(C-1"), 70.5(C-5") and 17.4(C-6").

Physcion (2). White powder, ${ }^{1} \mathrm{H}$ NMR (400 $\left.\mathrm{MHz}, \mathrm{CD}_{3} \mathrm{OD}\right): \delta 7.75(1 \mathrm{H}, \mathrm{m}, \mathrm{H}-7), 6.96(1 \mathrm{H}, \mathrm{d}, \mathrm{J}=$ $2.7 \mathrm{~Hz}, \mathrm{H}-5), 6.66(1 \mathrm{H}, \mathrm{m}, \mathrm{H}-4), 6.21(1 \mathrm{H}, \mathrm{m}, \mathrm{H}-2)$, 
$5.35(2 \mathrm{H}, s, 1-\mathrm{OH}$ and $8-\mathrm{OH}), 4.12(3 \mathrm{H}, \mathrm{s}, \mathrm{H}-3)$, $1.98(3 \mathrm{H}, \mathrm{s}, \mathrm{H}-6)$.

Antioxidant activity. Antioxidant activity was evaluated by using stable free radical $0.04 \%$ DPPH (1,1-diphenyl-2-picrylhydrazyl). Suitably diluted stock solutions were spotted on stained silica gel TLC plate and the plate was kept in the chambers containing solvent according to different polarities (polar, medium polar and non-polar) to resolve polar and non-polar components of the extract. The plate was seared at room temperature and was sprayed with $0.02 \%$ DPPH in ethanol. Due to wash out by $\mathrm{DPPH}$, resolved bands were observed for 10 minutes and the color changes (yellow on purple background) were observed. ${ }^{12}$

Stock solution of the crude drugs that means three fraction HSR, DSR and ESR were processed in methanol from which a serial dilution was executed to reach concentration of $1,5,10,50,100,500 \mu \mathrm{g} / \mathrm{ml}$. The new concentration of samples (each $2 \mathrm{ml}$ ) were mixed with $2 \mathrm{ml}$ of a $0.004 \%$ ethanol solution of DPPH and conceded to keep for 30 minutes for reaction to be found. The absorbance was examined at $517 \mathrm{~nm}$ and from these values the respective percentage of inhibitions were figured. $\mathrm{IC}_{50}$ value was calculated from the graph, which was arranged by plotting $\%$ of inhibitions against log concentration. The experiment was done 3 times and average absorption was noted for each concentration. ${ }^{13}$ Ascorbic acid was used as standard drug.

Antibacterial activity. Disc diffusion method ${ }^{14}$ was used for the estimation of antibacterial activity of HSR, DSR and ESR materials against a number of Gram (-)ve Bacillus cereus, B. megaterium, B. subtilis, Staphylococcus aureus, Sarcina lutea and the Gram (-)ve Escherichia coli, Pseudomonas aeruginosa, Salmonella paratyphi, S. typhi, Shigella boydii, Sh. dysenteriae, Vibrio mimicus, $V$. parahemolyticus, and three unicellular fungi Candida albicans, Aspergillus niger, Sacharomyces cerevacae. Test samples were prepared using sterile blank discs $(6 \mathrm{~mm})$ which were saturated with the test samples dissolved in methanol at concentration of $500 \mu \mathrm{g} /$ disc by a micropipette and used for the assay. After incubation as per the published method, the diameter of inhibitory zones formed around each discs were computed using digital slide calipers. ${ }^{15}$ Ciprofloxacin $(5 \mu \mathrm{g} / \mathrm{disc})$ and fluconazole $(5 \mu \mathrm{g} / \mathrm{disc})$ were used as positive controls for antibacterial and antifungal activities, respectively.

\section{RESULTS}

Phytochemical screening. Phytochemical screening of the different fractions of the plant extract by the standard methods revealed the presence of several phytoconstituents such as alkaloids, flavonoids, saponins, tanins and terpneoids as shown in Table 1.

Table 1. Result of phytochemical screening of extracts.

\begin{tabular}{cccccc}
\hline Test sample & Alkaloids & Saponins & Flavonoids & Tannins & Triterpenoids \\
\hline HSR & + & + & + & + & + \\
DSR & + & - & + & - & + \\
ESR & + & + & + & + & + \\
\hline
\end{tabular}

+ Presence, - Absence

Evaluation of antioxidant activity. Antioxidant activity of the tested fractions was evaluated according to the method specified above and the results are summarized in Table-2. Figure 1 depicts the percent inhibition of DPPH radicals upon increasing concentration of the compounds. The $\mathrm{IC}_{50}$ value of HSR, DSR, ESR and ascorbic acid were found to be $11.59,44.7,10.38$ and $6.05 \mu \mathrm{g} / \mathrm{ml}$, respectively. Among the extract, ESR showed the most prominent antioxidant property which is comparable to ascorbic acid. HSR and DSR also exhibited moderate antioxidant property.

Evaluation of antimicrobial activity. The antibacterial activity of HSR, DSR and ESR were evaluated at $500 \mu \mathrm{g} / \mathrm{disc}$ on the growth of pathogenic 
bacteria and fungi by the disc diffusion method and the results are summarized in Table 3 . The crude fractions designated as HSR, DSR and ESR exhibited antibacterial activity with an average zone of inhibitions 10.3-15.3 mm, $6.2-8.5 \mathrm{~mm}$ and 10.2- 16.8 $\mathrm{mm}$, respectively whereas standard ciprofloxacin
$(5 \mu \mathrm{g} / \mathrm{ml})$ showed $16-23 \mathrm{~mm}$. The results indicated that at the dose of $500 \mu \mathrm{g} /$ disc ESR and HSR accorded mild to moderate activity against both Gram (+)ve and Gram (-)ve strains than DSR fraction. However, ESR, HSR and DSR did not show any antifungal activity.

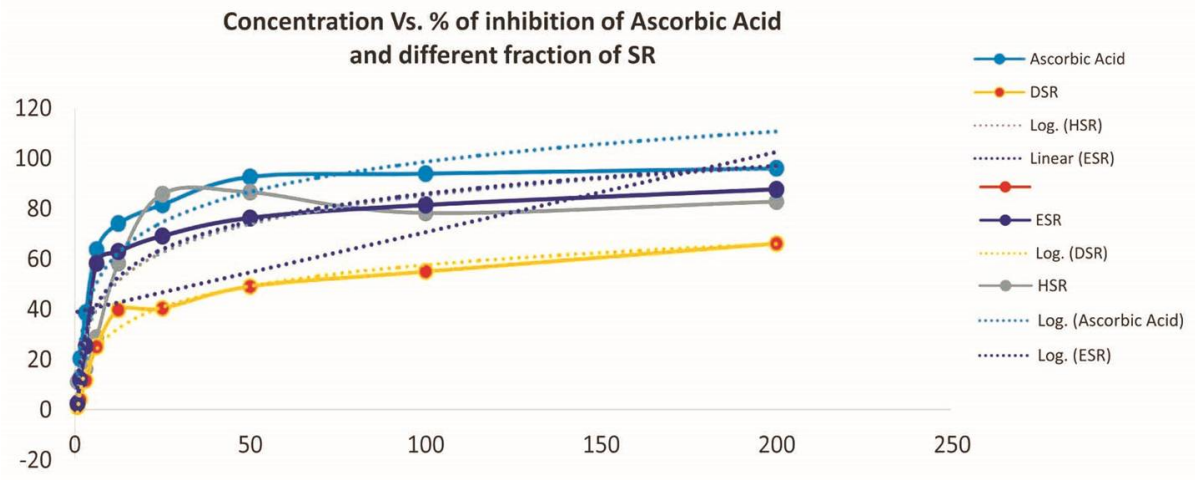

Figure 1. Concentration against \% of inhibition of HSR, DSR, ESR extract and ascorbic acid

Table 2. IC $_{50}$ values of HSR, DSR, ESR extract and ascorbic Acid.

\begin{tabular}{lccc}
\hline Test sample & \multicolumn{1}{c}{ Regression line } & $\mathrm{R}^{2}$ & $\mathrm{IC}_{50} \mu \mathrm{g} / \mathrm{ml}$ \\
\hline Ascorbic acid & $\mathrm{y}=17.353 \operatorname{In}(\mathrm{x})+18.713$ & 0.9142 & 6.05 \\
HSR & $\mathrm{y}=16.1336 \operatorname{In}(\mathrm{x})+9.905$ & 0.8551 & 11.59 \\
DSR & $\mathrm{y}=12.092 \operatorname{In}(\mathrm{x})+1.8883$ & 0.9785 & 44.7 \\
ESR & $\mathrm{y}=15.92 \operatorname{In}(\mathrm{x})+12.615$ & 0.9197 & 10.38 \\
\hline
\end{tabular}

*Ascorbic acid as standard

Table 3. Antimicrobial activity of the fractions against Gram positive and Gram negative bacteria.

\begin{tabular}{lcccc}
\hline & & Zone of Inhibition $(\mathrm{mm})$ & \\
Pathogens & HSR & DSR & ESR & Ciprofloxacin \\
& $(500 \mu \mathrm{g} / \mathrm{ml})$ & $(500 \mu \mathrm{g} / \mathrm{ml})$ & $(500 \mu \mathrm{g} / \mathrm{ml})$ & $(250 \mu \mathrm{g} / \mathrm{ml})$ \\
Bacillus cereus & $10.3 \pm 0.21$ & - & $14.2 \pm 0.43$ & $18 \pm 0.11$ \\
B. megaterium & $15.1 \pm 0.33$ & - & $15.1 \pm 0.22$ & $20 \pm 0.32$ \\
B. subtilis & $13.7 \pm 0.22$ & $7.1 \pm 0.45$ & $13.4 \pm 0.33$ & $19 \pm 0.23$ \\
Staphylococcus aureus & $11.1 \pm 0.66$ & - & $12.6 \pm 0.44$ & $17 \pm 0.26$ \\
Sarcina lutea & $14.2 \pm 0.11$ & $8.5 \pm 0.29$ & $12.4 \pm 0.22$ & $22 \pm 0.32$ \\
E. coli & $13.1 \pm 0.23$ & - & $10.5 \pm 0.42$ & $16 \pm 0.52$ \\
P. aeruginosa & $10.9 \pm 0.43$ & $6.2 \pm 0.33$ & $11.3 \pm 0.34$ & $17 \pm 0.34$ \\
S. paratyphi & $12.2 \pm 0.21$ & $7.4 \pm 0.23$ & $16.1 \pm 0.21$ & $23 \pm 0.44$ \\
S. typhi & $11.1 \pm 0.31$ & - & $10.2 \pm 0.22$ & $16 \pm 0.44$ \\
Sh. boydii & $13.3 \pm 0.21$ & $6.3 \pm 0.23$ & $16.8 \pm 0.20$ & $22 \pm 0.74$ \\
Sh. dysenteriae & $15.3 \pm 0.66$ & $6.5 \pm 0.66$ & $13.7 \pm 0.13$ & $18 \pm 0.43$ \\
V. mimicus & $14.7 \pm 0.31$ & - & $15.1 \pm 0.22$ & $21 \pm 0.53$ \\
V. parahemolyticus & $11.6 \pm 0.11$ & - & $13.7 \pm 0.12$ & $18 \pm 0.23$ \\
\hline
\end{tabular}

*values mentioned here Mean \pm standard deviation $(\mathrm{n}=3)$ 
Isolation of pure compounds from ESR extract. As the ESR fraction exhibited most prominent antioxidant and antibacterial properties, the fraction was subjected to isolation of active constituents. A total of three compounds (Figure 2) were isolated from ESR fraction of SR by column chromatography and PTLC. The high field NMR analysis was used for elucidation of structure of the isolated compounds and compared with published NMR data. The ${ }^{1} \mathrm{H}-\mathrm{NMR}$ spectrum (400 MHz, $\mathrm{CD}_{3} \mathrm{OD}$ ) of compound 1 revealed a pair of metacoupled aromatic doublet at $\delta 6.37 \mathrm{ppm}$ and 6.19 ppm corresponding to H-6 and H-8 protons, respectively and an ortho-coupled double doublets at $\delta 7.30 \mathrm{ppm}(J=8.0$ and $1.5 \mathrm{~Hz})$ for $\mathrm{H}-6^{\prime}$ protons. Another meta-coupling was observed between the protons of $\mathrm{H}-2^{\prime}$ and $\mathrm{H}-6^{\prime}$ at 7.35 and $7.30 \mathrm{ppm}$, respectively. The compound $\mathbf{1}$ was composed of quercetin, a flavonoid which linked to rhamnose, in the position of $\mathrm{C}_{3}$ via $\mathrm{C}-\mathrm{O}-\mathrm{C}$ bonding. The ${ }^{13} \mathrm{C}$ NMR spectrum of compound $\mathbf{1}$ displayed carbonyl group at $177.9 \mathrm{ppm}$ and other signals between 93.6- 164.6 ppm for aromatic carbons. The ${ }^{1} \mathrm{H}$ NMR and ${ }^{13} \mathrm{C}$

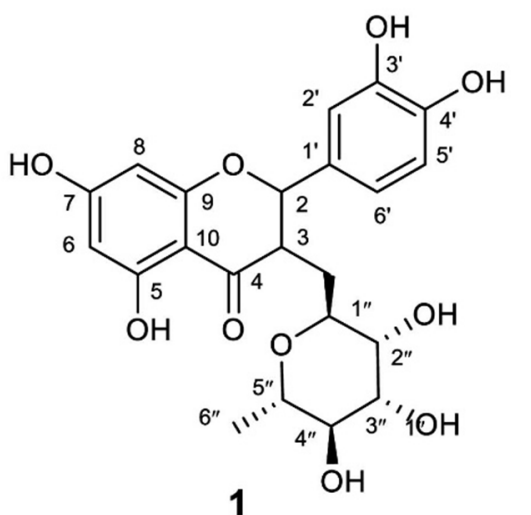

NMR spectral data of compound $\mathbf{1}$ was compared to reference value of quercitrin and found to be identical. ${ }^{16,17}$ Thus, compound $\mathbf{1}$ was identified as a flavonoid glycoside, quercitrin.

Compound $\mathbf{2}$ is a natural pigment, gave intense benzoid absorption band on the UV region ranges between 240-260 nm. ${ }^{18}$ Compound 2 displayed two pairs of meta-coupling proton at the position of H-7 \& $\mathrm{H}-5$ and $\mathrm{H}-2$ \& $\mathrm{H}-4$, respectively. Additionally, it showed a singlet for methoxy group at C-3 and a singlet at $5.35 \mathrm{ppm}$ for hydroxyl group corresponding to $\mathrm{H}-1$ and $\mathrm{H}-8$ which is resemblance to physcion and confirmed by comparison with previous report. ${ }^{19}$ On the other hand, the unknown compound gave two peaks only among which a singlet at $4.98 \mathrm{ppm}$ and another singlet at 1.91 with integrating $3 \mathrm{H}$. All these features indicated that unknown compound may also be a 9,10-anthraquinone derivative which is still under investigation. Thus, the two isolated compounds were characterized as quercitrin (1) and physcion (2). This is the first report of isolation of compound 2 from this plant.

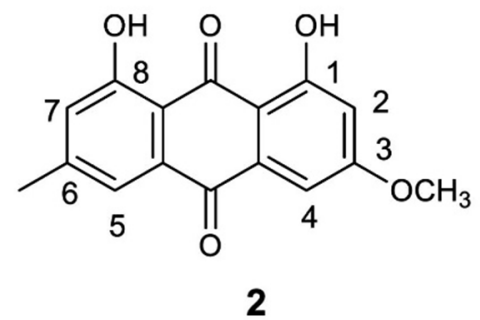

Figure 2. Structures of quercitrin (1) and physcion (2) isolated from S. rebaudiana

\section{DISCUSSION}

In this study, the plant extracts were fractionated into three major fractions namely HSR, DSR and ESR fractions. These fractions contained major phytoconstitutents which might be responsible for their activities. All the fractions exhibited antioxidant property. Antioxidant activity of the extracts depends on the ability to scavenge DPPH radical. DPPH stable free radical method is a most common method to determine the antioxidant activity of plant extracts. ${ }^{20,21}$ Many disorders like neurodegenerative diseases, cancer and AIDS are associated with over activity of free radicals and it is accepted that antioxidants due to their scavenging properties are 
useful for the management of those disease. Among the extracts, HSR and ESR provided promising antioxidant activity compared to standard ascorbic acid. The capability of $S$. rebaudiana extracts to scavenge DPPH could be accredited to the content of phenol, flavonoids as well as alkaloid as accentuated in several reports. ${ }^{22,}{ }^{23}$ Redox properties is mainly responsible for this activity which could be due to adsorbing and neutralizing free radicals, quenching singlet and triplet oxygen or decomposing peroxides. ${ }^{24}$ S. rebaudiana extract could play a vital role as a human diet to improve antioxidant intake. ${ }^{25}$ As it was found that ESR fraction showed most prominent antioxidant effect, it could be rationalized that the flavonoids and anthraquinone derivatives (compound 1-2) isolated from the fraction might be responsible for antioxidant activity because antioxidant is the common biological effects of both edible and non-edible plants containing flavonoids and phenolic compounds. ${ }^{26}$ Moreover, a study about the relationship of anthraquinone derivatives and their antioxidant activities concluded that hydroxyl groups either at meta or para position are responsible for the antioxidant activity. ${ }^{27}$ It has also been reported that not only the hydroxyl group, but also the carbonyl group of anthraquinone skeleton is responsible for the antioxidant potential. ${ }^{27}$

The drug from plant sources act as a prototype to produce less toxic and more effective medicines against the growth of microorganism. ${ }^{28}$ It is worthwhile to note that there are very few research works that have been done for antimicrobial activity of Stevia rebaudiana. In this study, we isolated three components quercitrin, physcion and an unidentified 9,10-anthraquinone derivatives from ESR fraction and this fraction showed prominent antioxidant and antibacterial activities than other fractions. It has been shown that the increase in concentration of quercitrin in culture media increase the linear value of inhibition zone. Quercitrin, a flavonoid, isolated from Dendrophthoe pentandra (L.) leaves is known to exhibit prominent antioxidant and antibacterial activities. ${ }^{16}$ Many reports have already explained the antibacterial and antifungal activities of anthraquinone isolated from natural sources. Two anthraquinones identified as emodin and physcion isolated from Vintilago madraspatana revealed antibacterial activity against three species of Bacillus. ${ }^{29}$ Therefore, It is well accepted that chemical compounds present in $S$. rebaudiana such as anthraquonone, alkaloids, flavonoids, tanins and triterpenoids play an important role in its antibacterial activity in vitro. ${ }^{30}$ As the crude drugs are complex in nature, all components might be synergistically or cumulatively responsible for their antibacterial activity.

\section{CONCLUSION}

In conclusion, three fractions (HSR, DSR and ESR) from $70 \%$ methanolic extract of $S$. rebaudiana were evaluated for antioxidant and antimicrobial properties. HSR and ESR fractions of the plants have demonstrated significant antioxidant and moderate antibacterial activities. Phytochemical investigation of ESR fraction provided three compounds (1, 2 and unidentified one). Among the three compounds, physcion is isolated first time from the plant $S$. rebaudiana. The plant material can be further studied extensively to isolate novel natural compounds by considering the potential bioactivity and scope which may persuade new drug development.

\section{REFERENCES}

1. Alhady, M.R.A.A. 2011. Micropropagation of Stevia rebaudiana (Bertoni), a new sweetening crop in Egypt. Global J. Biotech. Biochem. 6, 178-182.

2. Gantait, S., Das, A. and Banerjee, J. 2018. Geographical distribution, botanical description and self-incompatibility mechanism of Genus Stevia. Sugar Tech. 20, 1-10.

3. Chalapathi, M.V., Thimmegowda, S,. Sridhara, S,. Parama, V. and Prasad T.G. 1997. Natural non-calorie sweetener Stevia (Stevia rebaudiana Bertoni), a future crop of India. Crop Res. Hisar. 14, 347-350.

4. Pieri, V., Belanic, A., Morales, S. and Stuppner, H. 2011. Identification and quantification of major Dteviol glycosides in Stevia rebaudiana purified extract by ${ }^{1} \mathrm{H}-\mathrm{NMR}$ spectroscopy. J. Agric. Food Chem. 59, 4378-4384.

5. Kim, L.S., Yang, M., Lee, O.H. and Kang, S.N. 2011. The antioxidant activity and bioactive compound content of Stevia rebaudiana water extract. LWT-Food Sci. Technol. 44, 13281332. 
6. Tadhani, M.B., Patel, V.H. and Subhash, R. 2007. In vitro antioxidant activities of Stevia rebaudiana leaves and callus. J. Food Compos. Anal. 20, 323-329.

7. Yadav, A.K., Singh, S., Dhyani, D. and Ahuja, P.S. 2011. A review on the improvement of stevia [Stevia rebaudiana (Bertoni)]. Can. J. Plant Sci. 91, 1-27.

8. Alvarez-Robles, M.J., López-Orenes, A., Ferrer, M.A. and Calderón, A.A. 2016. Methanol elicits the accumulation of bioactive steviol glycosides and phenolics in Stevia rebaudiana shoot cultures. Ind. Crops Prod. 87, 273-279.

9. Tadhani, M.B. and Subhash, R. 2006. In vitro antimicrobial activity of Stevia Rebaudiana Bertoni leaves. Trop. J. Pharm. Res. 5, 557-560.

10 Kupchan, S.M., Tsou, G. and Sigel, C.W. 1973. Datiscacin, a novel cytotoxic cucurbitacin 20-acetate from Datisca glomerata. J. Org. Chem. 38, 1420-1421.

11. Nayak, B.S. and Pereira, L.M.P. 2006. Catharanthus roseus flower extract has wound-healing activity in Sprague Dawley rats. BMC Complement. Altern. Med. 6:41, 1-6.

12. Sadhu, S.K., Okuyama, E., Fujimoto, H. and Ishibashi, M. 2003. Separation of Leucas aspera, a medicinal plant of Bangladesh, guided by prostaglandin inhibitory and antioxidant activities. Chem. Pharm. Bull. 51, 595-598.

13. Braca, A. Tommasi, N.D., Bari, L.D., Pizza, C., Politi, M. and Morelli, I. 2001. Antioxidant principles from Bauhinia terapotensis.J. Nat. Prod. 64, 892-895.

14. Ríos, J.L., Recio, M.C. and Villar, A. 1988. Screening methods for natural products with antimicrobial activity: a review of the literature. J Ethnopharmacol. 23, 127-149.

15. Kelmanson, J.E., Jager, A.K. and Vaan, S.J. 2000. Zulu medicinal plants with antibacterial activity. $J$. Ethanopharmacol. 69, 241-246.

16. Hardiyanti, R., Marpaung, L., Adnyana, I.K. and Simanjuntak, P. 2019. Isolation of quercitrin from Dendrophthoe pentandra $(L)$ leaves and its antioxidant and antibacterial activities. Rasayan J. Chem. 12, 1822-1827.

17 Dutta, N. K; Mazumdar, K; Mishra, U.S; Dastidar, S.G; and Park, J.H. 2007. Isolation and identification of a flavone (quercetin) from Butea frondosa bark. Pharm. Chem. J. 41, 269-271.

18 Caro, Y., Anamale, L., Fouillaud, M., Laurent, P., Petit, T. and Dufosse, L. 2012. Natural hydroxyanthraquinoid pigments as potent food grade colorants: an overview. Nat. Prod. Bioprospect. 2, 174-193.
19. Barros, I.B.D., Daniel, J. F.D.S., Pinto, J.P., Rezende M.I., Filho, R.B. and Ferreira D.T. 2011. Phytochemical and antifungal activity of anthraquinones and root and leaf extracts of Coccoloba mollis on phytopathogens. Braz. arch. biol. technol. 54, 535-541.

20. Stevia, L.A; Savio, M; Cazzalini, O; Pizzala, R; Rehak, L; Bianchi, L., Vannini, V. and Prosperi, E. 1996. Effect of $\beta$ carotene on cell cycle progression of human fibroblast. Carcinogenesis. 17, 2395: 2401

21. Kumar, P.S; Sucheta, S; Deepa, V.S; Selvamani, P; Latha. S. 2008. Antioxidant activity in some selected Indian medicinal plants. Afr. J. Biotechnol. 7, 1826-1828.

22. Madsen, H.L; Neilsen, B.R; Bertelsen, G; Skibsted, L.H. 1996. Screening of antioxidative activity of spices. A comparison between assays based on ESR spin trapping and electrochemical measurement of oxygen consumption. Food Chem. 57, 331-337.

23. Moller, J.K.S; Madsen, H.L; Altonen, T; Skibsted, L.H. 1999. Dittany (Origanum dictamnus) as a source of water extractable antioxidants. Food Chemistry. 64, 215-219.

24. Zheng, W. and Wang, S.Y. 2001 Antioxidant activity and phenolic compounds in selected herbs. J. Agric. Food Chem. 49, 5165-5170.

25. Tahid, M.B., Patel, V.H. and Rema, S. 2007. In vitro antioxidant activities of Stevia rebaudiana leaves and callus. J. Food Compos. Anal. 20, 323-329.

26. Kahkonen, M.P., Hopia, A.I., Vuorela, H.J., Rauha, J.P., Pihlaja, K., Kujala, T.S. and Heinonen, M., 1999. Antioxidant activity of plant extracts containing phenolic compounds. $J$. Agric. Food Chem. 47, 3954-3962.

27. Huang, H.C., Lee, C.R., Chao, P.D.L., Chen, C.C. and Chu, S.S. 1991. Vasorelaxant effect of emodin, an anthraquinone from a Chinese herb. Eur. J. Pharmacol. 205, 289-294.

28. Ahmad, I. and Beg, A.Z. 2001. Antimicrobial and phytochemical, studies on 45 Indian medicinal plants against multiple drug resistant human pathogens. J. Ethnopharmacol. 74, 113-123

29. Basu, S; Ghosh, A; and Hazra, B. 2005. Evaluation of the antibacterial activity of Ventilago madraspatana Gaertn., Rubia cordifolia Linn. and Lantana camara Linn.: isolation of emodin and physcion as active antibacterial agents. Phytother. Res. 19, 888-894.

30. Belemtougri, R.G., Constantin, B., Cognard, C., Raymond, G. and Sawadogo L. 2006. Effects of two medicinal plants Psidium guajava L. (Myrtaceae) and Diospyros mespiliformis L. (Ebenaceae) leaf extracts on rat skeletal muscle cells in primary culture. J. Zhejiang Univ. Sci. B. 7, 56-63. 